\title{
Nudging Art Lovers to Donate
}

\author{
Boram Lee \\ (Corresponding author) \\ Accounting and Finance Division, \\ Stirling Management School, \\ University of Stirling, \\ Stirling, Scotland, UK, FK9 4LA \\ (E-mail: boram.lee@stir.ac.uk). \\ Ian Fraser \\ Accounting and Finance Division, \\ Stirling Management School, \\ University of Stirling, \\ Stirling, Scotland, UK, FK9 4LA \\ (E-mail: i.a.m.fraser@stir.ac.uk). \\ Ian Fillis \\ Faculty of Arts Professional and Social Studies, \\ Liverpool Business School, \\ Liverpool John Moores University, \\ Liverpool, UK, L3 5UG \\ (E-mail: i.r.fillis@ljmu.ac.uk).
}

\section{Author(s)' Note}

Special thanks go to Jeffrey Brudney, and to three anonymous referees. The authors also thank Martin Falk, Leonhard Lades, Marie Briguglio and participants at the 7th European Workshop on Applied Cultural Economics for useful comments. The AHRC UK Cultural Value Project funding is gratefully acknowledged. Our study was only possible with the support of the Royal Scottish Academy in Edinburgh and our research participants.

KEY WORDS willingness-to-donate; nudge; loss aversion; cultural value

Accepted for publication in Nonprofit and Voluntary Sector Quarterly by SAGE 


\begin{abstract}
Many nonprofit organizations face revenue uncertainty due to funding cuts. It is crucial for them to supplement existing revenue streams by private donations, and apply thoughtful market segmentation in their pursuit of donors. We introduce the behavioral concept of 'nudge' based on the possibility of loss aversion affecting willingness-to-donate, and investigate its implications for fundraising strategies. Potential donors are nudged to donate by the hypothetical scenario of 'losing' an existing exhibition, and also by that of 'gaining' an additional exhibition. We observe significant loss aversion effects as frequent gallery-goers donate more in order to avoid losing an exhibition. While both prospective gain and loss scenarios are effective in nudging non-frequent gallery-goers, the prospect of enjoying 'one more' event is observed to be stronger. We argue that there may be scope to increase support for nonprofit organizations, particularly in the cultural sector, by exploiting the psychological characteristics of prospective donors.
\end{abstract}




\section{Introduction}

Nonprofit arts organizations worldwide face revenue uncertainty which challenges their ability to deliver goods and services effectively (Hager, 2001). Although funding models vary according to national policy, arts organizations generally rely on various income sources including public funding, private sponsorship, sales and donations. In the USA, federal arts policy tends to favor the delegation of specific funding actions to private donors and arts professionals (Lewis and Brooks, 2005). In the UK, private investment, including individual giving, together with income from trusts, charitable foundations, and business investment, only accounts for $12 \%$ of total arts funding, while national and local government funding accounts for 51.5\%, with the remaining 36.5\% being earned income (Arts \& Business, 2012). Despite UK nonprofit arts organizations being heavily dependent on government funding, there has long been pressure to increase income from other sources given ongoing reduction in arts funding (Towse, 1994). Hansmann (1981) argues that arts organizations may have to engage in price discrimination in order to survive without public funding but that achieving this by ticket pricing may be challenging. Organizations which elicit donations from ticket purchasers, however, are effectively able to apply voluntary price discrimination; this may facilitate their survival in challenging times.

The need for fundraising by nonprofit organizations is not new and identifying effective ways to maximize private donations is challenging. Focusing on the detail of fund raising strategy, Kotler and Scheff (1997) argue that an understanding of market segmentation, e.g. differing donor interests, attitudes, and motivation, is essential to the creation of effective messages. Bennett (2003) emphasizes the connection between donors' personal values and those of the organization itself. As well as highlighting the importance of financial and socio-demographic background and of tax benefits to potential donors, he also identifies the importance of psychological antecedents, including empathetic predisposition, 
self-esteem, compassion and sense of social responsibility, and individual personality traits, in influencing willingness-to-donate. Additionally, for arts organizations, factors such as emotional response or aesthetic appeal (Guest, 2002) are likely to be important influences.

Given the potential significance of such psychological or emotional factors, the behavioral economics concept of 'Nudge' may be particularly relevant to the creation of communication messages designed to increase the level of donations to nonprofit organizations. Behavioral economic theory, unlike neo-classical theory based on rational utility maximization, assumes that individuals are prone to bias, emotional, myopic, easily confused and distracted (Ariely, 2010; Kahneman and Tversky, 2000; Kahneman, 2011). Behavioral economists believe that, by utilizing such personality flaws, individuals may be 'nudged' to enhance the quality of their decision-making (Slovic, 1995; Hausman and Welch, 2010).

In this paper, we investigate how 'Nudge' might be applied by a major visual arts gallery located in Scotland in order to increase private donations to a specific art exhibition. While existing research (e.g. Bertacchini et al., 2011; Kim and Van Ryzin, 2014) provides empirical evidence on willingness-to-donate to cultural organizations, as the first paper to introduce 'Nudge' together with the loss aversion effect of Prospect Theory (Kahneman and Tversky, 1979) within such a context, our work is innovative and has significant policy implications. O'Brien (2010) stresses that there is a lack of contingent valuation studies on arts and cultural organizations, and we believe that our study makes a significant contribution to filling this gap and to widening perspectives on public policy, business strategies, and fundraising for nonprofit organizations. We discuss the concept of 'Nudge' in more detail in the following section together with its application to the contingent valuation method (see e.g. Noonan, 2003) often used to elicit individual preferences. 


\section{Incorporating 'Nudge' in the Contingent Valuation Method}

'Nudge' summarizes the central idea underpinning any aspect of the choice architecture which aims to influence individuals in predictable ways by simple and cheap-to-run interventions while retaining individuals' freedom to choose options without significantly changing their economic incentives (Thaler and Sunstein, 2009). Interventions such as default options, personalization, salience and framing have been applied in various domains including health and well-being (Johnson and Goldstein, 2003), tax compliance (Bhargava and Manoli, 2015) and charitable giving (Behavioural Insights Team, 2013). A well-known example is the 'Save More Tomorrow' initiative of Thaler and Benartzi (2004), a prescriptive savings program which encourages employees to increase their rate of saving on receipt of a pay rise while reserving to them the ability to 'opt-out'.

'Nudge' enables accounting for the psychological flaws of individuals within the contingent valuation method (CVM). CVM is predicated on the assumption that individuals' revealed values are contingent upon hypothetical scenarios included in experiment-based surveys designed to elicit preferences in monetary terms for changes in the quantity or quality of non-market goods or services (Portney, 1994). CVM has been used to value public goods and environmental amenities (Hanemann, 1994; Carson et al., 1994), and since the seminal study of Throsby and Withers (1983), has become popular in arts and culture (Noonan, 2003; Martin, 1994). Examples include studies on the Royal Theatre, Copenhagen (Hansen, 1997), the British Museum (Jaffry and Apostolakis, 2011) and the Museum of Central Finland (Tohmo, 2004).

In contrast to our application, CVM in its 'traditional' form assumes that individuals' coherent and rational preferences enable them to be the 'best' judges of their welfare. Dolan and Metcalfe (2008), however, claim that a pervasive problem arises from the unrealistic assumptions which underpin the neo-classical economic paradigm. Sugden (2005) highlights 
a number of anomalies apparent in individuals' stated preferences exemplifying systematic deviations from the predictions of neo-classical economics. A well-known anomaly is the disparity between willingness-to-accept and willingness-to-pay when transacting goods or services (Plott and Zeiler, 2005). Knetsch and Sinden (1984) and Coursey, Hovis and Schulze (1987) account for this by the loss aversion effect (Kahneman and Tversky, 1979) which assumes that individuals are more sensitive to losses than to gains, and that prospective losses influence individuals by at least twice as much as do gains of the same magnitude. This paper is predicated on the assumption that loss aversion affects willingness-to-donate and we investigate the implications for nonprofit organizations' fundraising strategies.

Based on their identification of the factors motivating arts donations in Kentucky, Thompson et al. (2002) stress the benefits of incorporating different scenarios within a survey on the provision of arts events. They find that households are willing to donate more under scenarios eliciting donations to avoid a $25 \%$ reduction in the current number of art programs due to funding cuts, than they are under scenarios positing an increase in the number of art programs by $25 \%$. Although Thompson et al. (2002) do not emphasize psychological effects; their conclusions reflect the loss aversion effect (Kahneman and Tversky, 1979).

We build on the work of Thompson et al. (2002), by specifically applying the 'nudge' concept in order to identify the effectiveness of alternative fundraising strategies. Our study is carried out with the cooperation of the Royal Scottish Academy in Edinburgh, Scotland, UK (hereafter 'the gallery'). The gallery is an independent, privately-funded charitable organization led by eminent Scottish artists and architects, which receives no government funding. For the year ending 30 November 2012, the gallery reports total annual income of $£ 489,586$. About $50 \%(£ 226,835)$ is generated from its portfolio of listed investments (market value $£ 6.8 \mathrm{~m})$. About $25 \%(£ 125,289)$ derives from its rolling program of exhibitions, in the form of sales commission, admission and sponsorship. Awards, donations and legacies 
$(£ 42,605)$ account for $8.7 \%$ of income. Sales of paintings, drawings and furniture, picture rental and grants account for the remainder. The gallery has recently experienced disappointing investment returns. If current economic circumstances persist, private donations will assume greater importance as an element of recurring revenue.

With a mission to promote and support the visual arts, the gallery offers an all-year program of charged and free-entry exhibitions, in addition to residencies, scholarships and awards for artists and architects. Since 1976 the gallery has provided a platform for recent Scottish art college graduates to showcase their talents through the annual New Contemporaries Exhibition (hereafter 'the exhibition'). There are limited opportunities for graduating artists to engage with public audiences; the exhibition constitutes one such platform (Fillis, Lee and Fraser, 2015). While other exhibitions showcase the artworks of recent graduates in Scotland, the exhibition remains the largest such platform in terms of artist numbers and gallery capacity.

In 2014, the exhibition attracted over 7,000 visitors, and over 300 purchasable artworks were exhibited including installation works, oil paintings, watercolors, drawings, prints, sculpture, performance and architecture, by 64 artists, approximately 1 in 7 of the graduating students eligible, selected from each of the five art colleges and five architectural schools located in Scotland. We carry out a survey of visitors to the exhibition following the argument of Hansmann (1981) that donors who are also ticket buyers are effectively engaging in price discrimination voluntarily, i.e. they willingly pay more than is required. We believe that those who love art, and who are already present at the research site, are easier to 'nudge'. Thus our research hypothesis is applied only to exhibition visitors as described below.

\section{Research Hypothesis}

According to prospect theory (Kahneman and Tversky, 1979), the value function for individuals is defined by an S-shaped graph with a kink at the origin, indicating that 
individuals are conscious of even marginal changes to their prospects. Individuals perceive their prospects in terms of Gains and Losses defined relative to a reference point, the Status Quo (Tversky and Kahneman, 1991). The model is identified as concave for gains and convex for losses, and displays diminishing sensitivity in both directions as the magnitude of gains and losses increases. The slope for losses is about twice as steep as that for gains. This difference is a reflection of individuals' loss aversion, suggesting that the pain experienced as a result of losing a given amount is more than twice the pleasure produced by gaining the same amount.

To test the loss aversion effect, we create three different versions of a question on visitors' willingness-to-donate; two of the three versions incorporate hypothetical prospective scenarios. Firstly, the 'Unframed' version asks the question in the following form. "This exhibition is the only exhibition showcasing the artworks of Scotland's emerging talent. Supposing that the gallery was raising funds for the exhibition, how much would you be willing to donate?" This version of the question represents the current utility position of visitors and those who answer it are allocated to a control group.

Secondly, the 'Gain-framed' version changes the second sentence as follows: "Supposing that the gallery is raising funds to provide another platform similar to the exhibition for emerging artists within Scotland, how much would you be willing to donate?" Visitors allocated to this treatment group have the potential to move their utility from the Status Quo to the Domain of Gain. The question seeks to elicit visitors' willingness-to-donate in order to enjoy 'one more' similar event.

Thirdly, the 'Loss-framed' question changes the second sentence as follows: "Supposing that the gallery was in a position where it had to discontinue the exhibition because of financial constraints, how much would you be willing to donate in order for the gallery to be able to continue with the exhibition?" The question is administered to a second 
treatment group, creating the potential for visitors to move their utility from the Status Quo to the Domain of Loss through the hypothetical scenario of raising funds in order to prevent an outcome whereby there is no platform available for consumption; in effect this would mean that the exhibition itself is 'lost'.

The three versions of the question allow us to test whether the difference in willingness-to-donate stems from diminishing marginal utility of consumption; intuitively, there may be considerable benefit accruing from the first exhibition, but a second may be less beneficial. There is a single utility function indicating diminishing marginal utility with an additional exhibition, while there is a 'kink' in the function reflecting the impact of reducing the number of similar exhibitions from one to zero. In accordance with the loss aversion effect, we expect the scenario which postulates losing the exhibition to give rise to the highest willingness-to-donate. Thus we hypothesize that the average willingness-to-donate is highest for the loss-framed version, followed by the gain-framed, with the unframed version last.

If we observe greater willingness-to-donate by visitors allocated to the loss-framed version than to the others, this might provide a useful perspective, in terms of the potential effects of 'nudge', to gallery managers responsible for fundraising strategies. Nonetheless, the magnitude of the loss aversion effect may also be dependent on the level of interest which individual visitors have in visual art. Using 'the frequency of exhibition visits' as a proxy for the degree to which visitors are interested in visual art, we examine whether the loss aversion effect differs between frequent and non-frequent gallery-goers.

\section{Survey Construction}

Since the 1850 Public Libraries and Museums Act which permits free entry to museums and libraries, the UK public have become familiar with free access to cultural sites, taking the resultant benefits 'for granted' (Bailey and Falconer, 1998). As the gallery receives no governmental funding, entrance fees constitute one of its critical income sources. The 
exhibition was ticketed ( $£ 4$ standard, $£ 2$ concession), while gallery membership holders enjoy free admission along with a guest. Membership subscriptions cost between $£ 20$ and $£ 150$ annually. Due, however, to its location adjoining the publicly funded National Gallery of Scotland, which offers free admission, the gallery's funding status is often misunderstood. According to the 'crowding-out' hypothesis, government funding displaces or discourages private giving while the 'crowding-in' hypothesis claims the opposite (Schiff, 1990; Khanna and Sandler, 2000; Smith, 2003); such misunderstanding may cause adverse consequences in terms of falling donations (Abrams and Schmitz, 1984; Dokko, 2009). There is no consensus on crowding-out (in) effects, although many studies have investigated these complex phenomena (Brooks, 2000; Okten and Weisbrod, 2000; Andreoni and Payne, 2003; 2011; Kim and Van Ryzin, 2014). Horne, Johnson, and Van Slyke (2005), however, argue that they are more problematic when donors lack knowledge concerning the existence and levels of government funding. Thus we elicit visitors' perceptions of the entry price by informing only $50 \%$ of our respondents as to the funding status of the gallery in order to identify the effect on the respective amount which each group is willing to donate.

We create two versions of the survey question eliciting visitors' perceptions as to the entry price charged, 'Uninformed' and 'Informed', in order to account for the information effect in respect of funding status on willingness-to-donate. Survey respondents have options of 'Too little', ‘About right', and 'Too much' respectively from which to select their response. The 'Uninformed' control group receives the question in the following form. "What is your opinion of the entry fee charged?" The 'Informed' treatment group receives the question incorporating additional information as follows: "This gallery is an independent, privately-funded institution not receiving any core local or central government funding. What is your opinion of the entry fee charged?" 
The question eliciting perceptions of the entry fee was positioned within the survey immediately prior to that concerning visitors' willingness-to-donate. Thus responses to the willingness-to-donate question may be confounded by survey respondents' prior exposure to the question on entry fee. In order to disentangle the effect of these two interventions, we create six survey versions and distribute these randomly to visitors. Figure 1 presents our visitor allocations for the six versions of the survey based upon our experimental design and the number of individuals allocated to each version.

[Figure 1 here]

\section{Other Determinants of Willingness-to-Donate}

We conduct our survey on-site at the gallery, thus our sampling frame includes exhibition visitors only. A total of 675 visitors were surveyed; of those, 54 who did not provide responses to the most questions on socio-demographic backgrounds are excluded from our analysis, while we incorporate a 'not available' category to retain observations for those who did not answer the questions regarding gender, education level or household income. Thus our final sample size is 621 . In Table 1, we present responses to a set of socio-demographic questions included in the survey.

[Table 1 here]

We observe that $26.3 \%$ of respondents visit art exhibitions more than once a month; $20.5 \%$ visit about once a month, $22.1 \%$ visit between 5 to 8 times a year; $18.8 \%$ visit between 1 to 4 times a year; $8.1 \%$ visit less than once a year; and for $4.4 \%$, this was their first visit to an art exhibition. We classify those visitors who visit art exhibitions more than once a month as 'frequent gallery-goers' and the remainder as 'non-frequent gallery-goers'. When asked as to their perceptions of the entry fee charged, $86.8 \%$ of visitors indicate that it is 'about right', $7.4 \%$ state it is 'too little' and $5.8 \%$ that it is 'too much'. 
With regards to visitors' socio-demographic backgrounds, we observe that these are evenly balanced in terms of gender. The majority of visitors are of age group 18 to 34 $(52.2 \%)$ reflecting an apparently high interest among younger individuals. Many visitors have art-related occupations with $40.9 \%$ being art college students, artists, or employees of cultural institutions. The majority of respondents have either an undergraduate $(39.6 \%)$ or postgraduate degree $(21.4 \%)$. About $23.2 \%$ report gross annual household income of less than $£ 10,000$, reflecting a relatively high proportion of students and younger artists. We also observe that about $4.5 \%$ report gross annual household income in excess of $£ 100,000$.

Measures of economic valuation based solely on CVM may not fully encapsulate the exhibition's multidimensional features (Hutter and Throsby, 2008). Following Bakhshi and Throsby (2010), we test the proposition that economic valuations are influenced by experienced cultural and social values; i.e. the greater is visitors' cultural enjoyment of the exhibition, the more likely they are to donate (Throsby, 2001; 2003). The statement "I felt an emotional connection with the artworks." relates to the aesthetic, emotional and other 'connections' with the artworks experienced by visitors. If the exhibition has an emotional impact on visitors, we expect them to feel moved, excited, or affected (Guest, 2002; Locher, 2014). Thus the responses to this question provide information on important aspects of the cultural value created for visitors. Societal dialogues are known to maximize the impact of experience (Bakhshi and Throsby, 2010). We sought to identify whether visitors found discussing and conversing about the exhibition or the artworks with others to be an enjoyable experience, by presenting them with the statement "Talking about the artworks with other people was enjoyable" (Newman and McLean, 2004; Potts et al., 2008). Visitors were asked for their level of (dis)agreement with these two statements, which we define as 'Cultural value' and 'Social value' respectively, based on a 5 point Likert scale (1-'Not at all' and 5 'Very much'). We present the proportions of visitors responding on each scale point in Table 
1. We include these measures as dummy variables in our multivariate regression tests as determinants of visitors' willingness-to-donate by classifying those visitors who respond at above point 3 on the scale, i.e. those who either 'agree' or 'very much agree', following the approach of Terza (1987).

\section{Empirical Approaches}

\section{Univariate test results}

As shown in Panel A of Table 2, 323 visitors, approximately half our sample (621 visitors), completed the willingness-to-donate question. The reported values range from $£ 0$ to $£ 100$ after winsorization at the 95th percentile with a high concentration of zero values (43 observations, $13 \%$ ). The mean is $£ 12.04$; although the median of $£ 5$ indicates that values are positively skewed.

\section{[Table 2 here]}

Descriptive statistics, $p$-values for a two-tailed $t$-test on the mean and a Mann-Whitney test on the median values for differences between the respective groups, 'Unframed', 'Gain-framed', and 'Loss-framed', are compared as shown in Panel B of Table 2. Those visitors allocated to the 'Gain-framed' version exhibit the highest mean of $£ 15.08$; those allocated to the 'Lossframed' version the next highest of $£ 12.23$ while those allocated to the 'Unframed' version exhibit the lowest mean of $£ 8.74$. We observe statistically significant differences only when we compare the responses, in terms of mean values, for the 'Unframed' versions with those for the 'Gain-framed' (at the 5\% level) and 'Loss-framed' versions (at the 10\% level), respectively. No statistically significant differences are observed for mean values between the 'Gain-framed', and 'Loss-framed' versions in terms of responses by all visitors.

We also present descriptive statistics and univariate test results for frequent gallerygoers separately in Panel C of Table 2. The values reported for both 'Unframed' and 'Gainframed' versions are similar, with mean values of $£ 11.66$ and $£ 11.43$, respectively. Those 
allocated to the 'Loss-framed' version indicate a much higher mean of $£ 16.06$. We do not, however, identify any statistically significant differences between the three versions which may be due to small subsample sizes. To test our hypothesis regarding the loss aversion effect, we undertake a multivariate regression on visitors' willingness-to-donate.

\section{Multivariate Analysis}

In our multivariate regression model, the dependent variable is visitors' willingness-todonate, (measured in $£$ s), based on the responses of the 323 visitors, including those indicating a 'zero' donation, who answered the willingness-to-donate question. As an explanatory variable, we create a categorical dummy variable by interacting the three versions, 'Unframed', 'Gain-framed' and 'Loss-framed', developed to account for the loss aversion effect, with a dummy variable identifying frequent gallery-goers. The group of nonfrequent gallery-goers allocated to the 'Unframed' version is omitted as a reference category for comparison.

We control for visitors' perceptions as to the current exhibition entry price charged; i.e. whether it was 'Too little', 'About right' or 'Too much', while also taking account of the gallery funding status intervention which classifies survey respondents as either 'Uninformed' or 'Informed' by interacting two variables. Those who do not receive any funding status information, i.e. 'Uninformed', and perceive the entry fee as 'too little', are omitted from the regression for reference. We also control for the experienced values identified as 'Cultural' and 'Social' as well as the socio-economic backgrounds of visitors including their gender, occupation, education and level of household income. We exclude the age variable from our model due to its high correlation with the occupation variable, especially with the 'retired' category.

Our dependent variable remains skewed after omitting missing data with a high concentration at zero and a few observations exhibiting high donations. This violates the 
normality assumption of ordinary least squares, given the high probability that the error term is also skewed. We therefore use the Poisson pseudo-maximum-likelihood (PPML) estimator, as proposed by Silva and Tenreyro (2006), as an alternative method of accounting for zero values. This estimator gives consistent results regardless of the data distribution, and is valid with general forms of heteroskedasticity. Additionally, PPML gives consistent results when there are many dummy variables despite it being a nonlinear maximum-likelihood estimator.

\section{[Table 3 here]}

As shown in Table 3, we present the marginal effects of the PPML estimation on willingnessto-donate. We observe that non-frequent gallery-goers allocated to both 'Gain-framed' and 'Loss-framed' versions are willing to donate significantly more than those allocated to the 'Unframed' version (the reference category). Those allocated to the 'Gain-framed' version exhibit willingness-to-donate of about $£ 10$ more, and those allocated to the 'Loss-framed' version about $£ 5.50$ more, than those allocated to the 'Unframed’ version; these two effects are significant at the $1 \%$ and $5 \%$ levels, respectively. Thus the exhibition may have triggered a desire for more cultural events on the part of those who had been less exposed to these previously in that they appear to value the prospect of enjoying 'one more' event similar to the exhibition more than they do the prospect of losing the current exhibition. We observe a significant loss aversion effect exhibited by frequent gallery-goers. Frequent gallery-goers exposed to the loss-framed scenario, under which the gallery is in the position of having to discontinue the exhibition because of financial constraints, are willing to donate about $£ 9$ more than the reference category at the $5 \%$ significance level supporting our hypothesis.

The effects of perceptions as to the entry price charged, on visitors' willingness-todonate are significant when these perceptions are compared to those allocated to the reference category, who are uninformed about the gallery's funding status and who perceive the entry price charged as 'Too little'. According to Wald tests (not reported), those who 
perceive the price charged as either 'About right' or 'Too much' exhibit significantly lower willingness-to-donate than those perceiving the price charged as 'Too little'. These results are regardless of the gallery funding status information provision. Those visitors informed of the gallery's funding status do not exhibit greater willingness-to-donate than those uninformed. Additionally, the information effect regarding gallery funding status has no significant influence on visitors' perceptions of entry price.

We also observe significant influences deriving from visitors' socio-demographic backgrounds. In the case of those allocated to the reference category, those who are art college students, artists and retired, exhibit significantly higher willingness-to-donate than do students. Similarly for the reference category, those with college diplomas or undergraduate or postgraduate degrees exhibit higher willingness-to-donate than those whose highest level of education is secondary school. Finally, those with higher household incomes, between $£ 41,000$ and $£ 100,000$, exhibit significantly higher willingness-to-donate than those with household incomes of less than $£ 10,000$ for the reference category. These significant effects, especially for visitors' occupations, incomes and education levels, support previous literature on determinants of donor behavior. The identified differences in willingness-to-donate highlights the potential scope for thoughtful market segmentation of non-profit organizations when seeking to maximize donation income.

\section{Robustness Checks}

Due to the nature of stated preference techniques and the consequent necessity for the interrogation to be relatively complex, e.g. the use of open-ended questioning, almost $50 \%$ of survey participants left the willingness-to-donate question unanswered. Visitors may be unfamiliar with, or lack experience or time in, the specific case setting when formulating their preferences (Bedate, Herrero and Sanz, 2009). Although missing data are a common feature of CVM, we do not know whether they occur randomly in this case or whether, alternatively, 
those visitors who decline to answer the willingness-to-donate question share certain characteristics, such as low income or education levels, thus making them less likely to donate. If non-responses reflect adverse reaction to the question, omission of the missing observations may lead to sample selection bias and to average values computed being overstated.

In order to check for non-response bias, i.e. whether non-respondents share systematically different characteristics, we use the Heckman selection model (Heckman, 1979) to execute our robustness checks. The Heckman regression outcome model is constructed in the same manner as the PPML model. In our selection equation, the dependent variable takes a value of 1 for visitors who answer the question, including those indicating zero as well as positive willingness-to-donate values; and 0 otherwise, i.e. for missing values. Based on the total of 621 observations, this two-stage regression model not only accounts for the decisions of visitors on how much to donate but also their willingness to answer the question.

We include an additional variable in the selection model as an instrument which may determine visitors' decision to answer the willingness-to-donate question, but not the amount they are willing to donate. We believe that visitors' familiarity with the gallery, as a result, for example, of prior visits or knowledge of its operations (Hansmann, 1981), may influence their willingness-to-donate. Thus the question asks "Have you visited previous Royal Scottish Academy New Contemporaries Exhibitions?", and based on the $46.9 \%$ of respondents indicating 'Yes' and the $53.1 \%$ indicating 'No', we construct a dummy variable which is included in the selection in order to meet the exclusion restriction. In Table 4, we report the marginal effects of the maximum likelihood estimates of two equations where the selection and outcome equations are estimated simultaneously.

[Table 4 here] 
In Panel A of Table 4, we report the outcome regression results. We observe results which are comparable to our PPML estimates, although at reduced levels of significance. In terms of our research hypothesis, we still observe significant effects from the gain-framed scenario for non-frequent gallery-goers (at the $1 \%$ level) and the loss-framed scenario for frequent gallery-goers (at the 10\% level) on their willingness-to-donate. Non-frequent gallery-goers allocated to the gain-framed scenario are willing to donate $£ 8.69$ more than those allocated to the unframed scenario. The prospect of non-frequent gallery-goers enjoying 'one more' event similar to the exhibition has greater value for them than losing the exhibition. For frequent gallery-goers, however, the loss-framed message remains powerful. These results again underline that employing the loss aversion effect may not work in the same way for all individuals.

In Panel B of Table 4, we present the marginal effects from the Probit selection model, where we identify the characteristics of those who chose to answer the willingness-todonate question, i.e. 323 uncensored observations, compared to those who did not, i.e. 298 censored observations. We observe that those who have not previously visited the exhibition are about $12 \%$ less likely (significant at the $1 \%$ level) to respond to the willingness-to-donate question than those who have. The 'Social value' variable is significantly correlated with the probability of responding to the willingness-to-donate question. Those visitors who have enjoyed interactions with others during their visit are more likely to respond to the question than those who did not (at the 5\% significance level), stressing the importance of the group experience. Art college students are about 14\% more likely (at the $10 \%$ level) to answer the willingness-to-donate question while respondents designated as 'others' in terms of occupation are $43.5 \%$ less likely (at the $1 \%$ level) to do so than those who are students in general. Compared to those with household incomes of less than $£ 10,000$, those with household incomes in the categories of ' $£ 10,000$ to $£ 20,000$ ' and ' $£ 61,000$ to $£ 100,000$ ' 
exhibit significantly higher probabilities $(13.6 \%$ and $14.4 \%$, respectively) of responding to the question, while those who choose the 'Not Available' category exhibit less probability $(14 \%)$ of doing so. Once again, occupations, incomes and education levels are significant in determining whether or not visitors complete the willingness-to-donate question. Those who choose not to disclose their occupation or household income are less likely to answer the donation question, which may indicate either their lack of interest in completing the survey or their financial difficulties.

After estimating the Heckman selection model, we obtain a Likelihood-Ratio (LR) test result of independent equations. With regard to the relationship between the outcome and selection equations, the test fails to reject the null hypothesis confirming that the two error terms are uncorrelated, i.e. there is no serious sample selection issue. We do not argue that the Heckman model is superior to the PPML estimator as each has particular advantages and disadvantages. The PPML estimator, however, is consistent with the existence of heteroskedasticity, while the Heckman model is not. Consequently, we present results for both approaches in testing the robustness of our results.

Although our empirical analysis is grounded in our underlying theoretical assumptions, our findings should be interpreted with caution. We acknowledge that our study is subject to small sample size bias as well as other biases affecting survey based studies, e.g. self-selection. In particular, our visitor sample is heavily skewed towards a younger demographic with a lower than average income level, less life experience, and, possibly, less self-awareness of their preferences. These characteristics may affect their responses to the nudge points set for this study.

\section{Discussion and Implications}

Many nonprofit organizations worldwide are required to sustain service delivery within an environment characterized by significant revenue constraints. The Royal Scottish Academy is 
one such organization, presenting the New Contemporaries exhibition in order to support emerging artists and maintain its charitable mission grounded in the organization's history, belief, governance, and culture. Weisbrod (1977) views nonprofit organizations as private producers of public goods. The gallery attempts to meet the needs of recent art college graduates and other stakeholders by providing a sole platform which is not subsidized by national or local government. In response to the uncertainty regarding the gallery's recurring income as a result of austerity and economic downturn, we employ the 'nudge' concept as an innovative vehicle with a view to identifying possible methods of enhancing the level of private donations.

Exploiting the psychological concept of loss aversion as explicated in prospect theory (Kahneman and Tversky, 1979), we hypothesize that visitors allocated to a loss-framed scenario exhibit greater willingness-to-donate to the exhibition than those allocated to both gain-framed and unframed scenarios. We accept our hypothesis for part of our sample. We observe that frequent gallery-goers, those who visit art galleries more often than once a month, exhibit significantly greater willingness-to-donate when they are allocated to the lossframed scenario than when allocated to the two other scenarios. These findings are significant after controlling for experienced cultural and social values as determined by the subjective experiences of the exhibition and the socio-economic characteristics of visitors. Our findings support Coursey, Hovis and Schulze (1987) who find that loss aversion has serious implications for welfare economics and the valuation of public goods, despite those not being traded in the market. Kahneman and Knetsch (1992) also argue that contributions to, or 'purchase of', public goods are strongly related to moral satisfaction.

We also find that both gain- and loss-framed scenarios are effective when presented as 'nudges' to the non-frequent gallery-goers who constitute the majority of exhibition visitors, although the gain-framed scenario appears to be more effective than the loss-framed scenario. 
Throsby (2003) classifies cultural goods as experiential or addictive, arguing that demand is cumulative rather than diminishing over time. Thus, this phenomenon may influence the economic valuations of non-frequent gallery visitors. It may be that the value of cultural experiences to them is conceptually different to more general utility changes. They appear to never value the prospect of additional cultural experiences as a declining variable; the value created may be sustainable at a given level without diminishing. This may explain why, for non-frequent gallery-goers, the pleasure obtained from one more event similar to the exhibition is valued as much as the disappointment of losing the exhibition. Thus the validity of the loss aversion effect in given situations may be dependent upon both the nature of the goods or services applied and the personal characteristics of the consumer; this may point to another 'blind spot' within prospect theory in addition to those which have been already acknowledged (see e.g. Kahneman, 2011).

We note that the employment of 'wolf-at-the-door' fundraising strategies based on loss-framed scenarios, similar to the one in this study, may carry risk. If the proposed reduction in programming is hypothetical, it may only be possible to signal 'mortal danger' once; multiple false alarms risk forfeiting the trust of donors. Unless the organization seriously intends to actually reduce programming based on the reaction of donors, threatening reduced activity levels is likely to be viewed as unethical. Increases or decreases in programming should be grounded in an overall long-term strategy; such a strategy requires incorporating multiple managerial concerns in addition to income diversification. For example, galleries generally, have artistic, educational, community, curatorial, and stewardship roles to fulfill. Thus we recognize that the practical implications arising from our research should be implemented cautiously.

Both the principles and findings of our research are of interest to other arts and cultural institutions, their funders and other nonprofits, particularly given government- 
induced and austerity-led funding constraints in the UK and worldwide. At the same time, these constraints are juxtaposed with pressures on cultural organizations resulting from government policies aimed at widening cultural participation.

We acknowledge that nonprofit art organizations face other strategic management issues which we fail address in this paper. Given existing government policies which seek to widen cultural participation, however, it is crucial to encourage a self-sustainable environment for nonprofit arts and cultural organizations thus enabling them to supplement existing problematic revenue streams. By exploiting the psychological concepts, there is potential to 'nudge' art lovers to contribute more to the cultural economy. Our findings may be used to inform and manipulate the wording of direct and digital marketing communication messages, as well as to help shape the content of advertisements appealing for financial support. These and other 'nudge' ideas such as default options to increase membership levels, the development and introduction of donation games, and the personalization of messages when communicating with future donors are applicable to both arts and other nonprofit organizations. Although most charitable nonprofit organizations may be distinguished from the gallery which is the focus of the present case, by, for example, very different customer profiles, most or all rely on donations to make their operations sustainable and further research might usefully consider whether the findings of the present research might be portable to them. 


\section{Funding}

This paper is funded by the Art and Humanity Research Council (AHRC) Cultural Value Project and the Grant Number is [AH/L014750/1].

\section{Author Biographies}

Boram Lee, $\mathrm{PhD}$, is a lecturer in Accounting and Finance at the University of Stirling and her research specializes in the field of behavioural finance. She has, however, a wide range of research interests, covering valuation of arts and culture, art, conflict and well-being, and the economic aspects of the cultural and creative industries.

Ian Fraser is Professor of Accounting at the University of Stirling. He has previously worked at the University of Strathclyde and at Glasgow Caledonian University. Ian has a broad range of research interests including auditing, corporate governance, financial reporting and the valuation of artworks and similar forms of capital.

Ian Fillis is Professor of Entrepreneurship at Liverpool John Moores University, with research interests including small business, creativity, arts marketing and consumer research. He was recently Principal Investigator of a UK AHRC funded Cultural Value project. He has been a University of Tasmania Distinguished Visitor and the Bowater Visiting Research Fellow, Deakin University. 


\section{References}

Abrams, B. \& Schmitz, M. (1984). The crowding-out effect of governmental transfers on private charitable contributions: Cross section evidence. National Tax Journal, 37, 563-568.

Andreoni, J. \& Payne, A. A. (2003). Do Government Grants to Private Charities Crowd Out Giving or Fund-raising? American Economic Review, 93, 792-812.

Andreoni, J. \& Payne, A. A. (2011). Is crowding out due entirely to fundraising? Evidence from a panel of charities. Journal of Public Economics, 95, 334-343.

Ariely, D. (2010). Predictability Irrational: The Hidden Forces that Shape Our Decisions. London: HarperCollins.

Arts \& Business. (2012). Private investment in culture 2010/2011. Less public, more private? arts funding in a cold climate, London, England: Arts \& Business.

Bailey, S. J. \& Falconer, P. (1998). Charging for admission to museums and galleries: A framework for analysing the impact on access. Journal of Cultural Economics, 22, 167-177.

Bakhshi, H. \& Throsby, D. (2010). Culture of innovation: An economic analysis of innovation in arts and cultural organisations. London, England: National Endowment for Science, Technology and the Arts.

Bedate, A. M., Herrero, L. C. \& Sanz, J. A. (2009). Economic valuation of a contemporary art museum: correction of hypothetical bias using a certainty question. Journal of Cultural Economics, 33, 185-199.

Behavioural Insights Team. (2013). Applying behavioural insights to charitable giving. London: Cabinet Office.

Bennett, R. (2003). Factors underlying the inclination to donate to particular types of charity. International Journal of Nonprofit and Voluntary Sector Marketing, 8, 12-29.

Bertacchini, E., Santagata, W. \& Signorello, G. (2011). Individual support to cultural heritage. International Journal of Arts Management, 13, 41-54.

Bhargava, S., \& Manoli, D. (2015). Psychological Frictions and the Incomplete Take-Up of Social Benefits: Evidence from an IRS Field Experiment. American Economic Review, 105, 3489-3529.

Brooks, A. (2000). Public subsidies and charitable giving: Crowding out, crowding in, or both? Journal of Policy Analysis and Management, 19, 451-64.

Carson, R. T., Wilks, L. \& Imber, D. (1994). Valuing the preservation of Australia's Kakadu conservation zone. Oxford Economic Papers, 46, 727-749.

Coursey, D. L., Hovis, J. L. \& Schulze, W. D. (1987). The disparity between willingness to accept and willingness to pay measures of value. Quarterly Journal of Economics, 102, 679- 
690.

Dokko, J. (2009). Does the NEA crowd out private charitable contributions to the Arts? National Tax Journal, 62, 57-75.

Dolan, P. \& Metcalfe, R. (2008). Comparing willingness-to-pay and subjective well-being in the context of non-market goods. Centre for Economic Performance Discussion Paper, London School of Economics and Political Science.

Fillis, I., Lee, B. \& Fraser, I. (2015). Measuring the cultural value of the Royal Scottish Academy New Contemporaries Exhibition as a platform for emerging artists. Cultural Trends, 24, 245-255.

Guest, S. (2002). The value of art. Art, Antiquity and Law, 7, 305-316.

Hager, M. (2001). Financial vulnerability among arts organizations: A test of the TuckmanChang measures. Nonprofit and Voluntary Sector Quarterly, 30, 376-92.

Hanemann, M. W. (1994). Valuing the environment through contingent valuation. Journal of Economic Perspectives, 8, 19-43.

Hansen, B. T. (1997). The willingness-to-pay for the Royal Theatre in Copenhagen as a public good. Journal of Cultural Economics, 21, 1-28.

Hansmann, H. (1981). Nonprofit enterprise in the performing arts. Bell Journal of Economics, 12, 341-361.

Hausman, D. M. \& Welch, B. (2010). Debate: To nudge or not to nudge. Journal of Political Philosophy, 18, 123-136.

Heckman, J. (1979) Sample selection bias as a specification error. Econometrica, 47, 153 161.

Horne, C., Johnson, J. \& Van Slyke, D. (2005). Do charitable donors know enough-and care enough-about government subsidies to affect private giving to nonprofit organizations. Nonprofit and Voluntary Sector Quarterly, 34, 136-149.

Hutter, M. \& Throsby, D. (2008). Beyond price: Value in culture, economics and the arts. Cambridge University Press: New York.

Jaffry, S. \& Apostolakis, A. (2011). Evaluating individual preferences for the British Museum. Journal of Cultural Economics, 35, 49-75.

Johnson, E. J. \& Goldstein, D. (2003). Do defaults save lives? Science, 302, 1338-1339.

Kahneman, D. (2011). Thinking, fast and slow. London: Penguin.

Kahneman, D. \& Knetsch, J. (1992). Valuing public goods: The purchase of moral satisfaction. Journal of Environmental Economics and Management, 22, 57-70. 
Kahneman, D. \& Tversky, A. (1979). Prospect theory: An analysis of decision under risk. Econometrica, 47, 363-391.

Kahneman, D. \& Tversky, A. (2000). Choices, values, and frames. New York: Cambridge University Press.

Khanna, J. \& Sandler, T. (2000). Partners in giving: The crowding-in effects of UK governm ent grants. European Economic Review, 44, 1543-1556.

Kim, M. \& Van Ryzin, G. G. (2014). Impact of government funding on donations to arts organizations: A survey experiment. Nonprofit and Voluntary Sector Quarterly, 43, 910-925.

Knetsch, J. L. \& Sinden, J. A. (1984). Willingness to pay and compensation demanded: experimental evidence of an unexpected disparity in measures of value. Quarterly Journal of Economics, 99, 507-521.

Kotler, P. \& Scheff, J. (1997). Standing room only: Strategies for marketing the performing arts. Boston, MA: Harvard Business School Press.

Lewis, G. B., \& Brooks, A. C. (2005). A question of morality: Artists' values and public funding for the arts. Public Administration Review, 65, 8-17.

Locher, P. (2014). Contemporary experimental aesthetics: Procedures and findings. In: Ginsburggh, V. and Throsby, D. (eds) Handbook of the economics of art and culture. Amsterdam: Elsevier, 49-77.

Martin, F. (1994). Determining the size of museum subsidies. Journal of Cultural Economics, $18,255-270$.

Newman, A. \& McLean, F. (2004). Capital and the evaluation of the museum experience. International Journal of Cultural Studies, 7, 480-498.

Noonan, D. (2003). Contingent valuation and cultural resources: A meta-analytic review of the literature. Journal of Cultural Economics, 27, 159-176.

O'Brien, D. (2010). Measuring the value of culture: a report to the Department for Culture Media and Sport. London: DCMS.

Okten, C. \& Weisbrod, B. A. (2000). Determinants of donations in private nonprofit markets. Journal of Public Economics, 75, 255-272.

Plott, C. R. \& Zeiler, Z. (2005). The willingness to pay/willingness to accept gap, the "endowment effect," subject misconceptions and experimental procedures for eliciting valuations. American Economic Review, 95, 530-545.

Portney, P. R. (1994). The contingent valuation debate: Why economists should care. Journal of Economic Perspectives, 8, 3-17.

Potts, J., Cunningham, S., Hartley, H. \& Ormerod, P. (2008). Social network markets: A new 
definition of the creative industries. Journal of Cultural Economics, 32, 167-185.

Schiff, J. (1990). Charitable giving and government policy: An economic analysis. Westport, CT: Greenwood Press.

Silva, J. M. C. \& Tenreyro, S. (2006). The log of gravity. Review of Economics and Statistics, $88,641-658$

Slovic, P. (1995). The construction of preference. American Psychologist, 50, 365-37.

Smith, T. (2003). The effect of NEA grants on the contributions to nonprofit dance companies. Journal of Arts Management, Law, and Society, 33, 98-113.

Sugden, R. (2005). Anomalies and state preference techniques: A framework for a discussion of coping strategies. Environmental and Resource Economics, 32, 1-12.

Terza, J. (1987). Estimating linear models with ordinal qualitative regressors. Journal of Econometrics, 34, 275-291.

Thaler, R. \& Benartzi, S. (2004). Save more tomorrow: Using behavioral economics to increase employee saving. Journal of Political Economy, 112, 164-187.

Thaler, R. H. \& Sunstein. C. R. (2009). Nudge: Improving decisions about health, wealth and happiness. London: Penguin.

Thompson, E., Berger, M., Blomquist, G. \& Allen, S. (2002). Valuing the arts: A contingent valuation approach. Journal of Cultural Economics, 26, 87-113.

Throsby, D. (2001). Economics and culture. Cambridge: Cambridge University Press.

Throsby, D. (2003). Determining the value of cultural goods: How much (or how little) does contingent valuation tell us? Journal of Cultural Economics, 27, 275-285.

Throsby, D. \& Withers, G. (1983). Measuring the demand for the arts as a public good: theory and empirical results. In: Hendon, W. S. and Shanahan, J. L. (eds) Economics of Cultural Decisions. Cambridge, Mass: Abt Books, 177-191.

Tohmo, T. (2004). Economic value of a local museum Factors of willingness-to-pay. Journal of Socio-Economics, 33, 229-240.

Towse, R. (1994). Achieving public policy objectives in the arts and heritage. In: Peacock A. and Rizzo, I. (eds), Cultural economics and cultural policies. Kluwer: Dordrecht, 143-165.

Tversky, A. \& Kahneman, D. (1991). Loss aversion in riskless choice: A reference dependent model. Quarterly Journal of Economics, 106, 1039-1062.

Weisbrod, B. A. (1977). The voluntary nonprofit sector. Lexington, Mass: Lexington Books. 


\section{Figure 1. Experimental Survey Design}

This figure presents our experimental survey design based on two interventions and visitor allocations for each version.

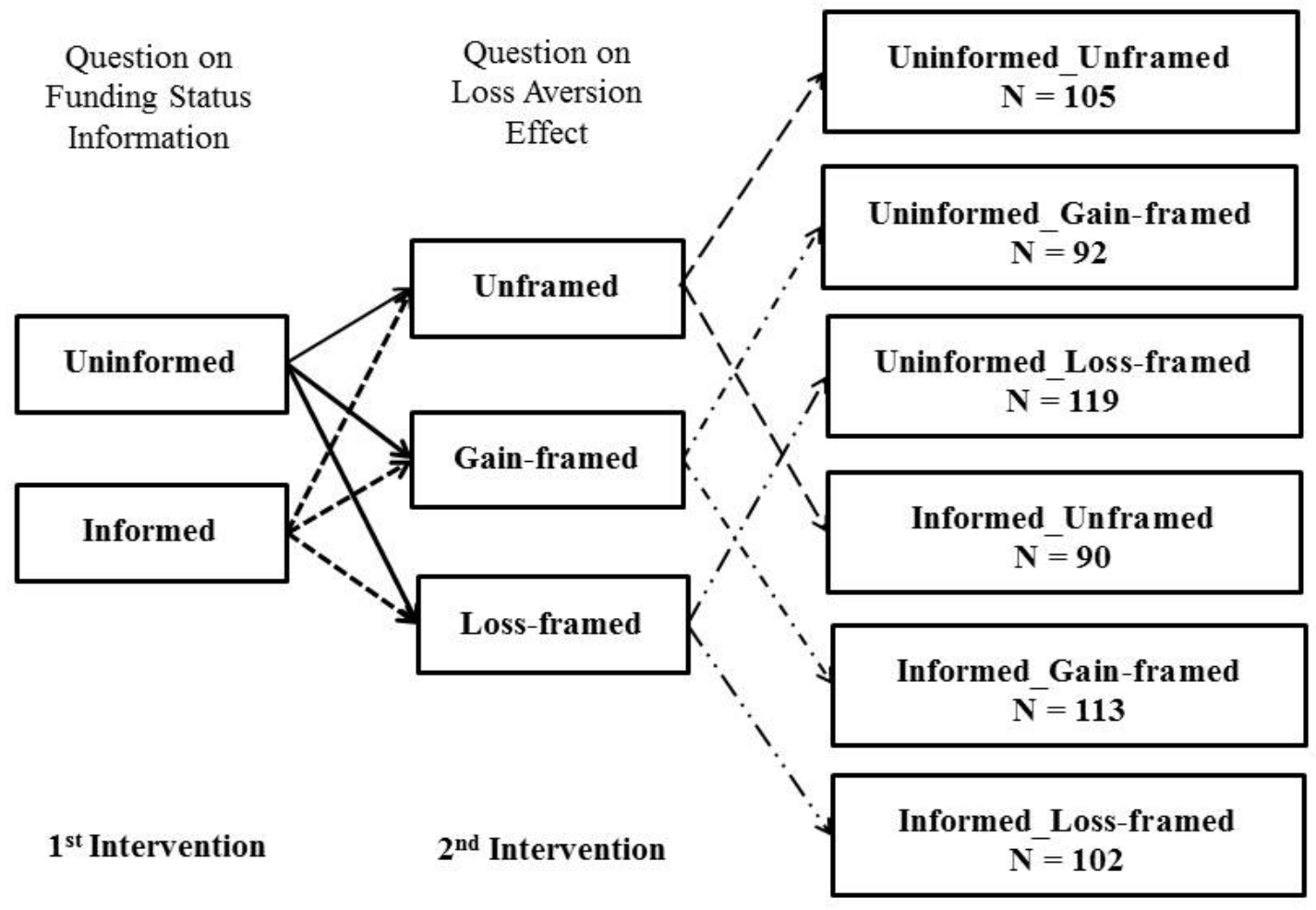




\section{Table 1. Determinants of the Willingness-to-Donate}

This table presents survey results and socio-economic background information for 621 participants. The statement which elicits visitors' experiential cultural value is "I felt an emotional connection with the artworks" while for social value, it is "Talking about the artworks with other people was enjoyable".

\begin{tabular}{|c|c|c|c|c|c|}
\hline Visit to Art Exhibitions & $\mathbf{N}$ & $\%$ & Entry Price Perception & $\mathbf{N}$ & $\%$ \\
\hline More than once a month & 163 & $26.25 \%$ & Too little & 46 & $7.41 \%$ \\
\hline About once a month & 127 & $20.45 \%$ & About right & 539 & $86.80 \%$ \\
\hline Between 5-8 times a year & 137 & $22.06 \%$ & Too much & 36 & $5.80 \%$ \\
\hline Between 1-4 times a year & 117 & $18.84 \%$ & Gender & $\mathbf{N}$ & $\%$ \\
\hline Less than once a year & 50 & $8.05 \%$ & Male & 308 & $49.60 \%$ \\
\hline First time & 27 & $4.35 \%$ & Female & 301 & $48.47 \%$ \\
\hline Age & $\mathbf{N}$ & $\%$ & Not Available & 12 & $1.93 \%$ \\
\hline Below 18 & 10 & $1.61 \%$ & Education & $\mathbf{N}$ & $\%$ \\
\hline $18-24$ & 170 & $27.38 \%$ & Secondary school & 80 & $12.88 \%$ \\
\hline $25-34$ & 154 & $24.80 \%$ & College diploma & 56 & $9.02 \%$ \\
\hline $35-44$ & 75 & $12.08 \%$ & University degree & 246 & $39.61 \%$ \\
\hline $45-54$ & 86 & $13.85 \%$ & Postgraduate degree & 133 & $21.42 \%$ \\
\hline $55-64$ & 76 & $12.24 \%$ & Professional qualification & 80 & $12.88 \%$ \\
\hline $65-74$ & 46 & $7.41 \%$ & Technical qualification & 18 & $2.90 \%$ \\
\hline $75+$ & 4 & $0.64 \%$ & Not Available & 8 & $1.29 \%$ \\
\hline Occupation & $\mathbf{N}$ & $\%$ & Income & $\mathbf{N}$ & $\%$ \\
\hline Student & 88 & $14.17 \%$ & Less than $£ 10,000$ & 144 & $23.19 \%$ \\
\hline Art college student & 117 & $18.84 \%$ & $£ 10,000$ to $£ 20,000$ & 88 & $14.17 \%$ \\
\hline Artist & 104 & $16.75 \%$ & $£ 21,000$ to $£ 30,000$ & 75 & $12.08 \%$ \\
\hline Arts practitioners & 33 & $5.31 \%$ & $£ 31,000$ to $£ 40,000$ & 69 & $11.11 \%$ \\
\hline Skilled manual & 41 & $6.60 \%$ & $£ 41,000$ to $£ 60,000$ & 77 & $12.40 \%$ \\
\hline Professional & 177 & $28.50 \%$ & $£ 61,000$ to $£ 100,000$ & 58 & $9.34 \%$ \\
\hline Retired & 49 & $7.89 \%$ & More than $£ 100,000$ & 28 & $4.51 \%$ \\
\hline Other & 12 & $1.93 \%$ & Not Available & 82 & $13.20 \%$ \\
\hline Cultural Value & $\mathbf{N}$ & $\%$ & Social Value & $\mathbf{N}$ & $\%$ \\
\hline 1-Not at all & 88 & $14.17 \%$ & 1-Not at all & 31 & $4.99 \%$ \\
\hline 2 & 171 & $27.54 \%$ & 2 & 67 & $10.79 \%$ \\
\hline 3 & 221 & $35.59 \%$ & 3 & 199 & $32.05 \%$ \\
\hline 4 & 121 & $19.48 \%$ & 4 & 207 & $33.33 \%$ \\
\hline 5-Very much & 20 & $3.22 \%$ & 5-Very much & 117 & $18.84 \%$ \\
\hline
\end{tabular}




\section{Table 2. Univariate Results on Willingness-to-Donate for the Exhibition}

This table presents descriptive statistics including values of mean, median, standard deviation, and the number of observations from visitors' responses on willingness-to-donate. Panel A) describes the sample distribution; Panel B) exhibits the descriptive statistics of the willingness-to-donate responses for all visitors while Panel C) is concerned with frequent gallery-goers only. We also report $p$ values from the univariate tests based on a twotailed t-test and a Mann-Whitney test (statistical significance: ** at the 5\%-level, * at the 10\%-level).

\section{Panel A) Sample Distribution}

\begin{tabular}{lcccc}
\hline \multicolumn{1}{c}{ Category } & Total sample & $\mathbf{\%}$ & Non-Missing subsample & $\%$ \\
\hline Willingness-to-Donate $=$ & 298 & $48 \%$ & & \\
Willingness-to-Donate $=0$ & 43 & $7 \%$ & 43 & $13 \%$ \\
Willingness-to-Donate $>0$ & 280 & $45 \%$ & 280 & $87 \%$ \\
Total & $\mathbf{6 2 1}$ & $\mathbf{1 0 0 \%}$ & $\mathbf{3 2 3}$ & $\mathbf{1 0 0 \%}$ \\
\hline
\end{tabular}

Panel B) Willingness-to-Donate by All Respondents

\begin{tabular}{|c|c|c|c|c|c|}
\hline Version & Mean & Median & Mode & S.D & $\overline{\mathbf{N}}$ \\
\hline All & $£ 12.04$ & $£ 5$ & $£ 10$ & $£ 19.24$ & 323 \\
\hline 'Unframed' & $£ 8.74$ & $£ 5$ & $£ 10$ & $£ 12.70$ & 99 \\
\hline 'Gain-framed' & $£ 15.08$ & $£ 5$ & $£ 5$ & $£ 25.24$ & 99 \\
\hline 'Loss-framed' & $£ 12.23$ & $£ 8$ & $£ 10$ & $£ 17.73$ & 125 \\
\hline \multicolumn{2}{|c|}{ Significance test } & t-value & p-value & ney test & p-value \\
\hline \multicolumn{2}{|c|}{ 'Unframed'-'Gain-framed'** } & -2.234 & 0.027 & -0.843 & 0.399 \\
\hline \multicolumn{2}{|c|}{ 'Unframed'-'Loss-framed'* } & -1.728 & 0.085 & -1.552 & 0.121 \\
\hline \multicolumn{2}{|c|}{ 'Gain-framed'-'Loss-framed' } & 0.983 & 0.327 & -0.595 & 0.551 \\
\hline
\end{tabular}

Panel C) Willingness-to-Donate by Frequent Gallery-Goers

\begin{tabular}{|c|c|c|c|c|c|}
\hline Version & Mean & Median & Mode & S.D & $\mathbf{N}$ \\
\hline All & $£ 13.29$ & $£ 5$ & $£ 5$ & $£ 22.53$ & 86 \\
\hline 'Unframed' & $£ 11.66$ & $£ 5$ & $£ 10$ & $£ 19.94$ & 32 \\
\hline 'Gain-framed' & $£ 11.43$ & $£ 5$ & $£ 5$ & $£ 23.01$ & 21 \\
\hline 'Loss-framed' & $£ 16.06$ & $£ 10$ & $£ 10$ & $£ 24.89$ & 33 \\
\hline Significance test & & t-value & p-value & itney test & p-value \\
\hline 'Unframed'-'Gain-framed' & & 0.038 & 0.970 & -0.798 & 0.425 \\
\hline 'Unframed'-'Loss-framed' & & -0.786 & 0.435 & -0.761 & 0.447 \\
\hline 'Gain-framed'-'Loss- & & -0.686 & 0.496 & -1.286 & 0.198 \\
\hline
\end{tabular}




\section{Table 3. PPML Estimates for Willingness-to-Donate}

This table presents marginal effects of the Poisson pseudo-maximum-likelihood (PPML) estimation results on willingness-to-donate based on 323 observations (statistical significance: *** at the 1\%-level, ** at the 5\%level, and $*$ at the $10 \%$-level). The estimated marginal effects $(\mathrm{dy} / \mathrm{dx})$ are reported.

\begin{tabular}{|c|c|c|c|}
\hline \multicolumn{2}{|c|}{ Willingness-to-Donate for the Exhibition_£ } & \multirow{2}{*}{$\frac{\mathbf{d y} / \mathbf{d x}}{10.318^{* * *}}$} & \multirow{2}{*}{$\frac{\text { z-value }}{3.10}$} \\
\hline Non-Frequent Gallery-goers & 'Gain-Framed' & & \\
\hline & 'Loss-Framed' & $5.511 * *$ & 2.06 \\
\hline \multirow[t]{3}{*}{ Frequent Gallery-goers } & 'Unframed' & 6.521 & 1.50 \\
\hline & 'Gain-Framed' & 3.682 & 0.66 \\
\hline & 'Loss-Framed' & $9.178^{* *}$ & 2.17 \\
\hline \multirow[t]{2}{*}{ No-Funding Status } & Entry Price 'About right' & $-8.351 * * *$ & -2.71 \\
\hline & Entry Price 'Too much' & $-8.643 * * *$ & -6.62 \\
\hline \multirow{3}{*}{ Funding Status Information } & Entry Price 'Too little' & $-4.728 * *$ & -1.97 \\
\hline & Entry Price 'About right' & $-8.868 * * *$ & -2.64 \\
\hline & Entry Price 'Too much’ & $-8.653^{* * *}$ & -13.11 \\
\hline \multirow{2}{*}{ Experienced Value } & Cultural Value & 2.382 & 1.07 \\
\hline & Social Value & 0.458 & 0.27 \\
\hline Gender & Female & 0.169 & 0.10 \\
\hline [ref: Male] & Not Available & -4.620 & -1.54 \\
\hline Occupation & Art college student & $12.673 * *$ & 2.43 \\
\hline \multirow{6}{*}{ [ref: Students] } & Artist & $11.342 * * *$ & 2.64 \\
\hline & Worker for a cultural institution & 5.647 & 1.11 \\
\hline & Skilled manual & -0.285 & -0.11 \\
\hline & Professional & 1.690 & 0.68 \\
\hline & Retired & $13.257^{*}$ & 1.90 \\
\hline & Other & $17.092 *$ & 1.79 \\
\hline Education & College diploma & $10.560 *$ & 1.72 \\
\hline \multirow[t]{5}{*}{ [ref: Secondary school ] } & University degree & $4.679 *$ & 1.87 \\
\hline & Postgraduate degree & $9.379 * *$ & 2.29 \\
\hline & Professional qualification & 2.724 & 0.65 \\
\hline & Technical qualification & -1.323 & -0.39 \\
\hline & Not Available & $11.017^{*}$ & 1.76 \\
\hline Household Income & $£ 10,000$ to $£ 20,000$ & 4.415 & 1.14 \\
\hline \multirow[t]{6}{*}{ [ref: Less than $£ 10,000$ ] } & $£ 21,000$ to $£ 30,000$ & $-2.984^{*}$ & -1.78 \\
\hline & $£ 31,000$ to $£ 40,000$ & 6.313 & 1.51 \\
\hline & $£ 41,000$ to $£ 60,000$ & $11.904^{* *}$ & 2.46 \\
\hline & $£ 61,000$ to $£ 100,000$ & $16.012 * *$ & 2.25 \\
\hline & More than $£ 100,000$ & 13.359 & 1.58 \\
\hline & Not Available & 4.511 & 1.23 \\
\hline R-squared & & & 0.25 \\
\hline
\end{tabular}




\section{Table 4. Heckman Selection Model on Willingness-to-Donate}

Panel A) Outcome Regression Results

This table presents the outcome regression results on willingness-to-donate for the Heckman selection model (statistical significance: $* * *$ at the $1 \%$-level, $* *$ at the $5 \%$-level, and $*$ at the $10 \%$-level). Based on 621 total observations, there were 298 censored observations and 323 uncensored observations. The estimated marginal effects $(\mathrm{dy} / \mathrm{dx})$ are reported.

\begin{tabular}{|c|c|c|c|}
\hline \multicolumn{2}{|c|}{ Willingness-to-Donate for the Exhibition (in $\mathfrak{f}$ ) } & \multirow{2}{*}{$\begin{array}{l}\mathbf{d y} / \mathbf{d x} \\
8.690^{* * *}\end{array}$} & \multirow{2}{*}{$\frac{\text { z-value }}{2.81}$} \\
\hline Non-Frequent Gallery-goers & 'Gain-Framed' & & \\
\hline & 'Loss-Framed' & 4.124 & 1.35 \\
\hline \multirow[t]{3}{*}{ Frequent Gallery-goers } & 'Unframed' & 3.977 & 1.00 \\
\hline & 'Gain-Framed' & 3.482 & 0.75 \\
\hline & 'Loss-Framed' & $6.639 *$ & 1.69 \\
\hline \multirow[t]{2}{*}{ No-Funding Status } & Entry Price 'About right' & $-12.612 * *$ & -2.12 \\
\hline & Entry Price 'Too much' & $-19.068^{* *}$ & -2.48 \\
\hline \multirow[t]{3}{*}{ Funding Status Information } & Entry Price 'Too little' & -8.933 & -1.29 \\
\hline & Entry Price 'About right' & $-12.731 * *$ & -2.13 \\
\hline & Entry Price ‘Too much’ & -20.730 & -1.07 \\
\hline \multirow[t]{2}{*}{ Experienced Value } & Cultural Value & 2.974 & 1.22 \\
\hline & Social Value & -0.274 & -0.12 \\
\hline Gender & Female & 0.029 & 0.01 \\
\hline [ref: Male] & Not Available & -3.091 & -0.33 \\
\hline Occupation & Art college student & $7.996^{* *}$ & 2.18 \\
\hline \multirow{6}{*}{ [ref: Students] } & Artist & $7.386^{*}$ & 1.95 \\
\hline & Worker for a cultural institution & 4.025 & 0.76 \\
\hline & Skilled manual & -1.384 & -0.27 \\
\hline & Professional & 0.523 & 0.14 \\
\hline & Retired & $11.152 * *$ & 2.29 \\
\hline & Other & 8.558 & 0.47 \\
\hline Education & College diploma & $8.186^{*}$ & 1.85 \\
\hline \multirow[t]{5}{*}{ [ref: Secondary school ] } & University degree & 4.355 & 1.30 \\
\hline & Postgraduate degree & $7.711 * *$ & 2.05 \\
\hline & Professional qualification & 0.951 & 0.22 \\
\hline & Technical qualification & -1.201 & -0.19 \\
\hline & Not Available & 8.873 & 0.94 \\
\hline Household Income & $£ 10,000$ to $£ 20,000$ & 3.343 & 0.98 \\
\hline \multirow[t]{6}{*}{ [ref: Less than $£ 10,000$ ] } & $£ 21,000$ to $£ 30,000$ & -2.603 & -0.71 \\
\hline & $£ 31,000$ to $£ 40,000$ & 5.348 & 1.28 \\
\hline & $£ 41,000$ to $£ 60,000$ & $11.087 * * *$ & 2.80 \\
\hline & $£ 61,000$ to $£ 100,000$ & $11.075^{* * *}$ & 2.70 \\
\hline & More than $£ 100,000$ & $10.912 *$ & 1.83 \\
\hline & Not Available & 4.791 & 1.16 \\
\hline
\end{tabular}


Panel B) Selection Model Results

This table presents the selection regression results on willingness-to-donate for the Heckman selection model based on the Probit regression (statistical significance: $* * *$ at the $1 \%$-level, $* *$ at the $5 \%$-level, and $*$ at the $10 \%$-level). The estimated marginal effects $(\mathrm{dy} / \mathrm{dx})$ are reported.

\begin{tabular}{|c|c|c|c|}
\hline \multicolumn{2}{|c|}{ Participating in the Willingness-to-Donate Question (0/1) } & \multirow{2}{*}{$\begin{array}{r}\mathbf{d y} / \mathbf{d x} \\
0.052\end{array}$} & \multirow{2}{*}{$\begin{array}{c}\text { z-value } \\
0.84\end{array}$} \\
\hline Non-Frequent Gallery-goers & 'Gain-Framed' & & \\
\hline & 'Loss-Framed' & 0.064 & 1.04 \\
\hline \multirow{3}{*}{ Frequent Gallery-goers } & 'Unframed' & 0.080 & 0.93 \\
\hline & 'Gain-Framed' & $-0.154 *$ & -1.86 \\
\hline & 'Loss-Framed' & 0.056 & 0.67 \\
\hline \multirow[t]{2}{*}{ No-Funding Status Information } & Entry Price 'About right' & $-0.231 *$ & -1.76 \\
\hline & Entry Price 'Too much' & -0.210 & -1.35 \\
\hline \multirow[t]{3}{*}{ Funding Status Information } & Entry Price 'Too little' & 0.132 & 0.79 \\
\hline & Entry Price 'About right' & -0.182 & -1.36 \\
\hline & Entry Price 'Too much' & $-0.479 * * *$ & -6.53 \\
\hline Previous Visit to the Exhibition & No & $-0.118 * * *$ & -2.62 \\
\hline \multirow[t]{2}{*}{ Experienced Value } & Cultural Value & 0.053 & 1.00 \\
\hline & Social Value & $0.113 * *$ & 2.54 \\
\hline Gender & Female & 0.023 & 0.52 \\
\hline [ref: Male] & Not Available & -0.164 & -0.99 \\
\hline Occupation & Art college student & $0.138^{*}$ & 1.83 \\
\hline \multirow[t]{6}{*}{ [ref: Students] } & Artist & 0.040 & 0.49 \\
\hline & Worker for a cultural institution & -0.017 & -0.15 \\
\hline & Skilled manual & -0.055 & -0.52 \\
\hline & Professional & -0.043 & -0.55 \\
\hline & Retired & -0.013 & -0.13 \\
\hline & Other & $-0.435 * * *$ & -4.35 \\
\hline Education & College diploma & -0.067 & -0.70 \\
\hline \multirow{5}{*}{ [ref: Secondary school ] } & University degree & -0.045 & -0.63 \\
\hline & Postgraduate degree & -0.050 & -0.62 \\
\hline & Professional qualification & -0.035 & -0.38 \\
\hline & Technical qualification & 0.020 & 0.15 \\
\hline & Not Available & -0.006 & -0.03 \\
\hline & $£ 10,000$ to $£ 20,000$ & $0.136^{*}$ & 1.87 \\
\hline \multirow[t]{6}{*}{ [ref: Less than $£ 10,000$ ] } & $£ 21,000$ to $£ 30,000$ & 0.065 & 0.82 \\
\hline & $£ 31,000$ to $£ 40,000$ & -0.052 & -0.62 \\
\hline & $£ 41,000$ to $£ 60,000$ & -0.026 & -0.32 \\
\hline & $£ 61,000$ to $£ 100,000$ & $0.144^{*}$ & 1.68 \\
\hline & More than $£ 100,000$ & -0.070 & -0.58 \\
\hline & Not Available & $-0.141^{*}$ & -1.91 \\
\hline \multirow{2}{*}{\multicolumn{2}{|c|}{ Pseudo R-squared }} & & 0.11 \\
\hline & & Coef & Std.Err \\
\hline \multicolumn{2}{|l|}{$\overline{\text { rho }}$} & -0.16 & 0.20 \\
\hline \multicolumn{2}{|l|}{ sigma } & 17.68 & 0.78 \\
\hline \multicolumn{2}{|l|}{ lambda } & -2.90 & 3.59 \\
\hline
\end{tabular}

